\title{
VIOLÊNCIA CONTRA TRANSGÊNEROS: CONSTRUINDO CARTOGRAFIAS ETNOGRÁFICAS
}

Lucas Mendes Pinheiro

Universidade Federal do Maranhão

lucas.pinheiro15@hotmail.com

Kalyl Mendes Farias

Universidade Federal do Maranhão

kalyl.william@gmail.com

Amanda Viégas Aramaki

Universidade Federal do Maranhão

amanda_aramaki@hotmail.com

Raquel Gomes Noronha

Universidade Federal do Maranhão

raquelnoronha79@gmail.com

Resumo: O presente artigo aborda o processo de criação de uma cartografia social que tem como tema A Violência Contra os Transgêneros, desenvolvida na disciplina de Projeto Gráfico II. A Internet foi uma valiosa ferramenta de pesquisa porém o foco do foi dado à pesquisa etnográfica. As informações foram coletadas e simplificadas para serem aplicadas a um banner a ser apresentado ao fim da disciplina.

Palavras-chave: Transgêneros, Cartografia Social, Etnografia.

Abstract: This article shows the creation process of a social cartography, about Violence Against Transgender developed in the discipline of Graphic Design II. Internet was a valuable tool for the research but the focus of the was the ethnographic research. Information was collected and organized to be applied in a banner and the result was shown in the end of the discipline.

Keywords: Transgender, social cartography, ethnography 


\section{INTRODUÇÃO}

Este artigo visa mostrar o processo de desenvolvimento de uma cartografia social realizado na disciplina de Projeto Gráfico II. Foi apresentada a metodologia de cartografia e de etnografia. Inicialmente definiu-se o tema geral sobre violência e foram retirados tópicos de relevância, dentre eles estaria o escolhido para ser trabalhado, Violência contra travestis. Todavia, devido as restrições do assunto e a escassez de informações, optou-se por ampliar o tópico para Violência contra Transgêneros.

Geralmente vinculado às camadas mais conservadores, essas atitudes são reflexos da ignorância acerca da realidade da vida dos transgêneros, assim como outros fatores sociais que replicam esteriótipos e/ou direcionam a uma falta de visibilidade, tais como o alto índice de marginalização, baixa escolaridade, envolvimento com prostituição e defasagem de dados estatísticos.

E munido desse conhecimento, partiu-se para a aplicação das técnicas e metodologias, o uso dos recursos cartográficos, a ida ao campo e a experiência etnográfica, os quais permitem um conhecimento melhor da causa abordada e dos envolvidos. Com todo esse aparato metodológico preenchido, o próximo passo foi a produção gráfica, iconização e sintetização das informações para que o infográfico, que com as informações adquiridas pelos métodos tomados, ao abordar uma questão social, sem tomar o local de fala dos representados e nem esteriotipá-lo, e que desperte interesse e fomente discussões.

\section{METODOLOGIA DE CARTOGRAFIA E DESDOBRAMENTO NO DESIGN}

Na disciplina nos foi apresentado o método da cartografia aplicada ao design. Cartografia na sua definição pela Associação Cartográfica Internacional (ACl) e ratificada pela Organização das Nações Unidas para a Educação, a Ciência e a Cultura é definida como "a atividade que se apresenta como o conjunto de estudos e operações científicas, técnicas e artísticas que, tendo por base os resultados de observações diretas ou da análise de documentação, voltam-se para a elaboração de mapas, cartas e outras formas de expressão ou representação de objetos, elementos, fenômenos e ambientes físicos e socioeconômicos, bem como a sua utilização.

Nas ciências sociais ela é uma metodologia usada para aprender algo próprio do seu campo, mas no design é utilizada para analisar e compreender sobre que vai além do seu campo de estudo, gerando assim reflexão visual.

A cartografia como metodologia de pesquisa-reflexão-intervenção nos propõem uma reversão metodológica como dizem Eduardo Passos, Virginia Kastrup e Liliana Da Escóssia:

Por sua vez a cartografia nos propõem uma reversão metodológica: transformar o méta-hódos em hódos-méta. Essa reversão consiste numa aposta na experimentação do pensamento - um método não para ser aplicado, mas para 
ser experimentado e assumido como atitude. Com isso não se abre mão do rigor mas ele é ressignificado. (PASSOS, KASTRUP, ESCÓSSIA, 2014, p.10)

Assim nesta pesquisa, ao invés de priorizar o fim, dá-se maior importância ao meio do processo, ou seja, não partindo com regras prontas nem objetivos preestabelecidos, estando abertos a descobertas, reflexões e entendimento. Sem determinar metas foi feita uma pesquisa geral tendo como tema a violência sobre transexuais. Entrevistas individuais e grupos focais reunidos para falar, avaliar, apontar problemas e soluções sobre o tema e principalmente relatar suas experiências em seus ambientes, o que é de grande importância para o método cartográfico, pois ele não visa, como a ciência moderna, separar o objeto de suas conexões, como diz L. da Escóssia e S.Tedesco:

[...] a cartografia não visa isolar o objeto de suas articulações históricas nem de suas conexões com o mundo. Ao contrário, o objetivo da cartografia é justamente desenhar a rede de forças à qual o objeto ou fenômeno em questão se encontra conectado [...] (PASSOS, KASTRUP, TEDESCO, 2014. p.57)

Esse método apresenta vantagens perante os outros no que diz respeito à descoberta, pois não há a predominância da busca pela informação, e sim uma busca pelo convite ao encontro, assim como diz Barbara Szaniecki, "levou a pensar no método cartográfico para projetar com design[...] respeitando e valorizando os sujeitos, as subjetividades, os poderes e saberes ali presentes". (SZANIECKI, 2013) Desta forma, o método cartográfico, diferente da ciência moderna, vê o objeto de estudo como um parceiro no projeto, produzindo conhecimento juntos e valoriza o meio, ou seja, o processo mais que o fim ou o resultado, absorvendo forças e fortalecendo conexões.

Vários autores em áreas diferentes de estudo já vêm utilizando essa metodologia em pesquisa:

[...] Felix Guattari e Suely Rolnik publicam no Brasil Cartografias do Desejo onde traçam conexões entre psicologia e política, com base em produções desejantes. O livro produziu muitos efeitos e alguns deles foram reunidos recentemente por Eduardo Passos, Virginia Kastrup e Liliana da Escóssia na publicação Pistas do método da cartografia. Nele, vários autores examinam o "método cartográfico" nas áreas da saúde e da clínica, da cognição e da educação brasileira e, em particular, as questões que atravessam essas práticas e outras afins [...] (SZANIECKI, 2013)

Dentro do projeto, havia o requisito da produção de um infográfico, e a metodologia de cartografia auxiliou na melhor forma de exposição de ideias. 0 conteúdo em si é bem vasto e pela própria estrutura da mancha gráfica É possível perceber que o texto, nesta disposição, ficava menos atrativo a leitura. 


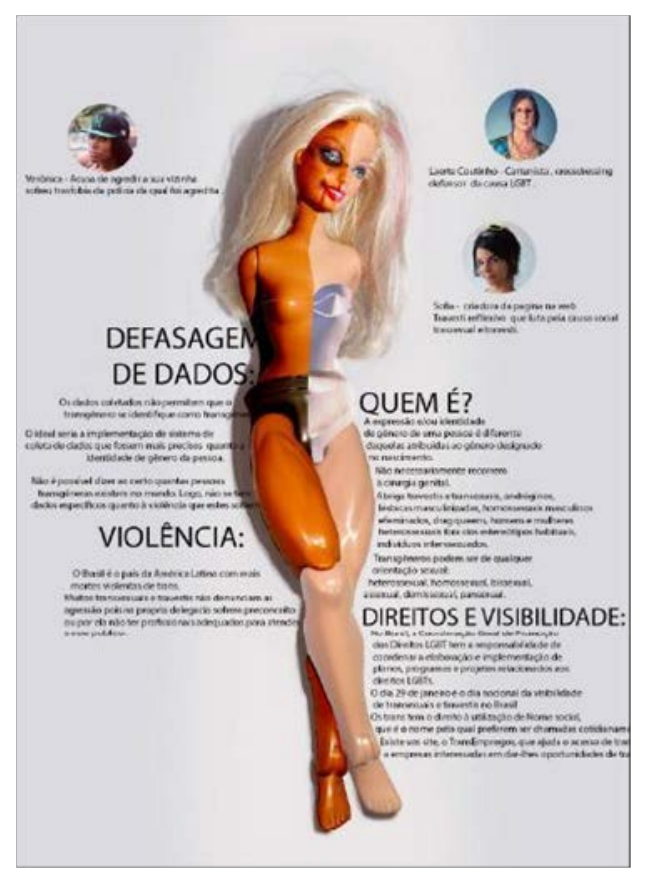

Figura 1 - Estudo de disposição de informação Fonte: "Elaborado pelos autores"

A ideia é que o infografico permeie informação, que fosse um iniciador de discussões, que todo o seu conteúdo mapeie uma realidade, e para facilitar isso, o uso de ícones é essencial. Além de despertar o interesse do leitor também ilustram o texto que acompanham.

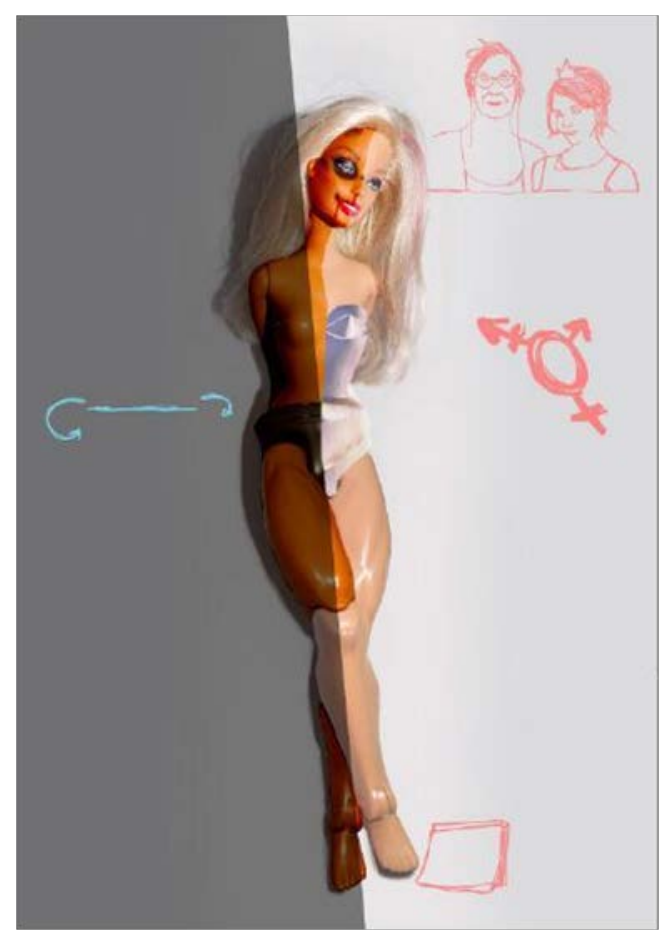

Figura 2 - Estudo de espaçamento de ícones Fonte: "Elaborado pelos autores" 


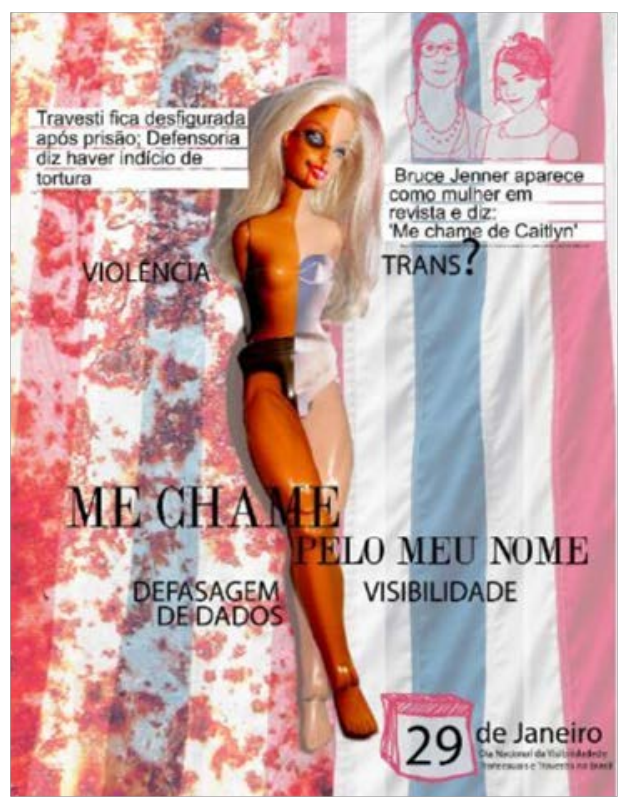

Figura 3 - Primeira Proposta sujeita a avaliação Fonte: "Elaborado pelos autores"

Dando continuidade ao processo feito na primeira proposta e seguindo algumas indicações sugeridas chegou-se a um resultado.

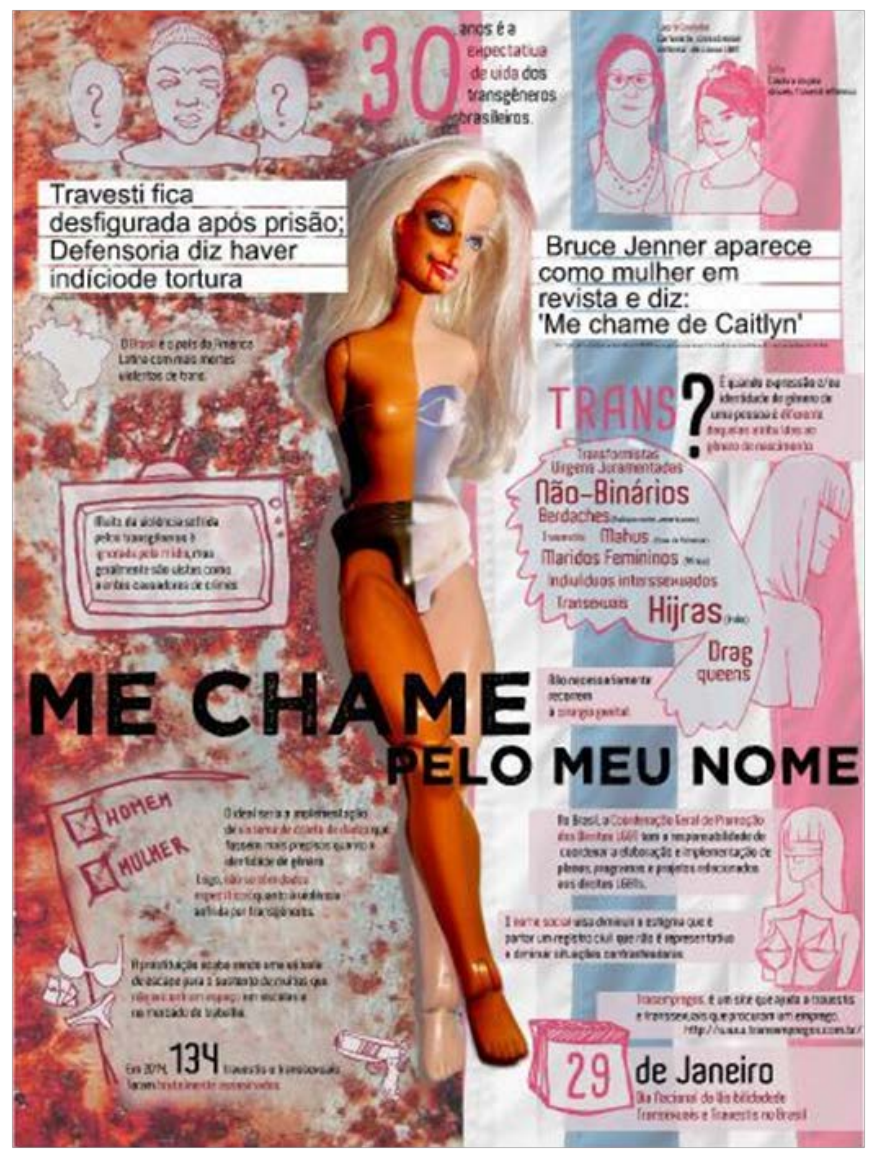

Figura 4 - Versão Final

Fonte: "Elaborado pelos autores" 


\section{ENTENDIMENTO DE ETNOGRAFIA E O IMPACTO NO PROJETO}

A etnografia é uma linha da antropologia. [...]Implica em tentar entender as pessoas, não suas personalidades, aspectos psicológicos ou movimentos sociais, mas as pessoas como seres embutidos em 'redes de significado'. (BELL, 2004, apud SOUZA, ROGERIO, 2005, p. 7)

Para melhor abordar o tema, um viés etnográfico seria a melhor escolha, pois valoriza individualidade de um grupo e expõe a cultura de um povo como exemplo de uma experiência vivida, não apenas pelo pesquisador, mas também pelo alvo da pesquisa. Primeiramente buscou compreender sobre o assunto, então, se iniciou uma prospecção para recolher referências que pudessem nortear o caminho que a princípio, era de total desconhecimento. Como dizem Passos, Kastrup e Tedesco, "a pesquisa de campo geralmente coloca o cartógrafo diante de um território que ele não conhece".

Para então compreender o motivo da violência era necessário primeiramente saber o que vem a ser transgênero.

O termo transgênero data dos anos oitenta. Sua origem é geralmente atribuída a Virgínia Prince, que o cunhou para designar travestis masculinos heterossexuais nos seus pioneiros livros de autoajuda intitulada "O Travesti e Sua Esposa e Como Ser Uma Mulher Sendo Homem (The Transvestite and His Wife e How To Be a Woman though Male)". Refere-se à condição onde a expressão e/ou identidade de gênero de uma pessoa é diferente daquelas atribuídas ao gênero designado no nascimento. (IANZ, [s.d.])

O significado atual foi um resultado de anos de estudos, pesquisas e lutas. 0 processo de visibilidade trans estende-se até os dias de hoje e para entender cada particularidade desse grupo fazem-se divisões para tornar mais compreensível a sua complexidade.

Dessa maneira, o termo passou a abrigar travestis e transsexuais (tanto masculinos quanto femininos), andróginos, lésbicas masculinizadas, homossexuais masculinos afeminados, drag-queens, gente que prefere responder a novos pronomes ou a nenhum, homens e mulheres heterossexuais fora dos estereótipos habituais, indivíduos intersexuados, membros diferenciados de certas sociedades, como os Berdaches norteamericanos, as Hijras indianas, os Mahu da Polinésia, os Xanith Omani, os "maridos femininos" africanos e as "virgens juramentadas" dos Bálcãs. (IANZ, [s.d.])

Tal definição só se tornou comum após os escritos de Leslie Feinberg (ativista transgênero, lésbica, e escritora).

Após algum conhecimento geral sobre o assunto, o próximo passo era vivenciar o campo de pesquisa. Foram entrevistadas 5 (cinco) pessoas, sendo 3 (três) transsexuais não opeados, 1 (um) gênero-fluido, e 1 (um) transformista performático. Foram feitas perguntas para entender como vivem, as dificuldades do dia-a-dia e como reagem à violência, ou seja, em casa ou nas ruas. Cada reunião foi filmada e transcrita. 
Também houve a tentativa de contactar travestis que vivem da prostituição, porém as tentativas de entrevista foram recusadas.

"Para que um trabalho de Etnografia ocorra, segundo Spradley (1979), é necessário três fontes de informação fundamentais: o que as pessoas falam, como elas agem, e o que elas usam." (IANZ, [s.d.])

Isto é, muito mais que texto transcrito, as reações captadas no tom de voz, na expressão corporal são chave para entender uma realidade. Depois desse amplo entendimento da causa, é que se une a etnografia ao design. Pois, "a etnografia procura entender a cultura humana, o Design se destina a desenvolvê-la". (ARAÚJO, 2012 p. 17)

A etnografia foi a ferramenta utilizada para compreender o meio e os problemas que o cercam e para que no momento da criação não se expusesse uma realidade superficial e estereotipada. Em contrapartida as metodologias do design servem para melhor explorar a pouca visibilidade e abordagem da violência nesse meio que encontrase na pesquisa etnográfica.

Foi necessário adaptar a pesquisa etnográfica para que ela coubesse no limite de tempo das avaliações, contudo, a ideia de "empréstimo" de métodos dá-se justamente pelo Design ser uma área multidisciplinar.

O resultado de uma etnografia cuja origem é acadêmica é motivado por objetivos científicos, onde se procuram análises longas e padrões de comportamento. Está nascendo um novo processo de Etnografia fora da academia, que tem uma limitação de tempo e escopo. Este novo processo não busca desenvolver teorias sobre comportamento, mas sim entender o que no cotidiano das pessoas pode se tornar oportunidade de projeto. (ARAÚJO, 2012 p. 15)

\section{RELAÇÕES LIMITANTES ENTRE O TEMA E OS MÉTODOS}

Fica bem claro que por meio desses métodos busca-se uma representação íntima e inclusiva de um tema, exclui-se uma visão generalista valorizando-se as peculiaridades.

O homogêneo diz respeito à uniformização dos modos de vida, discursos e opiniões, onde se destaca o papel da mídia e outros dispositivos da globalização, conduzindo a uma ditadura discreta e insidiosa. (PASSOS, KASTRUP, TEDESCO, 2014, p. 20)

O universo transgênero é pouco explorado e muito estigmatizado pela sociedade, por ir contra ao padrões, marginalizam-se da sociedade. Por isso a importância de dar visibilidade, trazer em voga esse assunto para debates.

O uso dos métodos abordados tem uma série de vantagens, tendo em vista que há um sério problema de dados estátisticos, e a pesquisa etnográfica consegue validar dados por meio da entrevista de várias pessoas integrantes do grupo, o conjunto de experiências dá suporte a criação de uma da realidade que condiz com aquele tema. 
A produção acerca de um assunto onde quem cria não vive aquela realidade abre lacunas para que o produto disso seja superficial ou estereotipado, já com a participação do grupo abordado pelo tema torna a representação fiel e facilita o acolhimento pela mesma.

\begin{abstract}
Este tipo de abordagem resulta numa valorização da identidade e cultura - e consequente valorização do sujeito -, a partir do momento em que passamos a observar todo o universo sociocultural das pessoas a quem o projeto se dirige. Além disso, como outro elemento importante, temos o artefato criado, fruto desta metodologia projetual, como identificador e difusor dessa cultura e identidade. (SOUZA FILHO, NORONHA, SANTOS, 2007, p. 4)
\end{abstract}

Contudo, tornar-se íntimo para acessar assuntos delicados, durante o período letivo de uma disciplina, pode acabar causando um certo distanciamento entre entrevistador e entrevistado, como diz no artigo Design Etnográfico, uma proposta metodológica, nem tudo é falado pelos informantes (SOUZA FILHO, NORONHA,SANTOS, 2007, p.6) , ou seja, para captar o maior número de informação, é necessário perceber as sutilezas que não são ditas com palavras, detalhes que não podem ser percebidos com pouco contato.

\title{
5. CONCLUSÃO
}

A criação do mapa da violência contra trangêneros a partir do método da cartográfia e da etnografia nos permitiu obter um visão geral e profunda desse assunto que ainda é considerado tabu pela sociedade e ainda há pouco interesse pela mídia. $\mathrm{E}$ unindo o design e cartográfia como ferramenta para dar essa visibilidade, conclui-se que ela é uma ótima ferramenta para causar reflexões e debates sobre o assunto, e em casos como o abordado, onde há uma considerável falta de dados estátisticos, essas metodologias conseguem abraçar de maneira eficiente,

\section{REFERÊNCIAS}

ARAÚJO, Eduardo Puçu de. Um estudo sobre etnografia aplicada ao Design. Disponível em: <http://www.maxwell.vrac.puc-rio.br/20854/20854.PDF> Acesso em: 2016

IANZ, Letícia. Transgênero: um histórico do termo. Disponível em: <http://www.leticia-lanz.org/transgenero-umhistorico-do--termo/> Acesso em: 2015. PASSOS, Eduardo; KASTRUP, Virgínia; ESCÓSSIA, Liliana da. Pistas do método da cartografia: pesquisa-intervenção e produção de subjetividade - vol 1. ed. Cidade: Editora.

PASSOS, Eduardo; KASTRUP, Virgínia; TEDESCO, Silvia. Pistas do método da cartografia: pesquisa-intervenção e produção de subjetividade - vol 2. ed. Cidade: Editora. ANO.

SOUZA FILHO, Benedito; NORONHA, Raquel Gomes; SANTOS, Camila Andrade dos. Design Etnográfico: uma proposta metodológica. ed. Cidade: Editora. 2007

DE SOUSA, Cleison; DE PAULA, Rogério. Etnografia (em CSCW). Disponível em: <http:// www.ufpa.br/cdesouza/teaching/topes/2-ethnography.pdf> Acesso: 2014. 